\title{
BMJ Open Determinants of virological failure among adults on first-line highly active antiretroviral therapy at public health facilities in Kombolcha town, Northeast, Ethiopia: a case-control study
}

Habtamu Mengist Meshesha, ${ }^{1}$ Zelalem Mehari Nigussie (D) , ${ }^{2}$ Anemaw Asrat, ${ }^{2}$ Kebadnew Mulatu ${ }^{2}$

To cite: Meshesha HM, Nigussie ZM, Asrat A, et al. Determinants of virological failure among adults on firstline highly active antiretroviral therapy at public health facilities in Kombolcha town Northeast, Ethiopia: a casecontrol study. BMJ Open 2020;10:e036223. doi:10.1136/ bmjopen-2019-036223

- Prepublication history for this paper is available online To view these files, please visit the journal online (http://dx.doi. org/10.1136/bmjopen-2019036223).

Received 18 December 2019 Revised 12 May 2020 Accepted 11 June 2020

Check for updates

(C) Author(s) (or their employer(s)) 2020. Re-use permitted under CC BY-NC. No commercial re-use. See rights and permissions. Published by BMJ.

${ }^{1}$ Ethiopian Field Epidemiology Training Program, Bahir Dar University, Bahir Dar, Amhara Region, Ethiopia

${ }^{2}$ Department of Epidemiology and Biostatistics, School of Public Health, College of Medical and Health Sciences, Bahir Dar University, Bahir Dar, Amhara region, Ethiopia

Correspondence to Mr Zelalem Mehari Nigussie; zelalem2011@gmail.com

\section{ABSTRACT}

Objective To identify determinants of virological failure among HIV-infected adults on first-line highly active antiretroviral therapy at public health facilities in Kombolcha town, Northeast, Ethiopia, in 2019.

Methods An unmatched case-control study was conducted from April to May 2019. About 130 cases and 259 controls were selected by simple random sampling. Data were extracted from charts of patients using a structured checklist. Multiple logistic regression analysis was performed to identify possible factors. HosmerLemeshow goodness of fit test was used to check the model. Finally, independent predictor variables of virological failure were identified based on adjusted $\mathrm{OR}$ (AOR) with $95 \% \mathrm{Cl}$ and a $p$ value of 0.05 .

Results The odds of virological failure were 2.4-fold ( $A 0 R=2.44,95 \% \mathrm{Cl} 1.353$ to 4.411 ) higher in clients aged $<35$ years compared with older clients, fivefold (AOR=5.00, 95\% $\mathrm{Cl} 2.60$ to 9.63) higher in clients who did not disclose their HIV status, threefold ( $\mathrm{AOR}=2.99$, $95 \% \mathrm{Cl} 1.33$ to 6.73 ) higher in clients with poor adherence, and 7.5-fold ( $\mathrm{AOR}=7.51,95 \% \mathrm{Cl} 3.98$ to 14.14) higher in clients who had recent CD4 count of $\leq 250$ cells $/ \mathrm{mm}^{3}$. Conclusion and recommendation This study revealed that age, marital status, occupation, disclosure status, baseline functional status, missed clinic visit, current antiretroviral therapy regimen, adherence to treatment and recent CD4 count were significantly associated with virological failure. Therefore, adherence support should be strengthened among clients. Missed clinic visits should also be reduced, as it could help clients better adhere to treatment, and therefore boost their immunity and suppress viral replication.

\section{BACKGROUND}

The prognosis for people with HIV has considerably improved since the introduction of highly active antiretroviral therapy (HAART) in $1996 .{ }^{12}$ The preferred first-line regimen for adults and adolescents is TDF (Tenofovir Disoproxil Fumaratev)+3TC (Lamivudine) + DTG (dolutegravir) or TDF+3TC+EFV (Efavirenz)
Strengths and limitations of this study

- Two consecutive viral load measurements were considered, avoiding misclassification of HIV treatment failure.

- It was impossible to include clients' primary data.

- Despite the recommendation of dolutegravir-based regimen for first-line therapy, its use has not started during the study period and was therefore not considered.

- The analysis was not corrected for non-nucleoside reverse transcriptase inhibitor-based regimen independently.

as a once-daily dose. However, in Ethiopia the use of DTG-based regimen has not started during this study period. Therefore once-daily regimens comprising nucleoside reverse transcriptase inhibitors backbone $(\mathrm{TDF}+3 \mathrm{TC})$ and one non-nucleoside reverse transcriptase inhibitor (EFV) are being used as the preferred choice in adults. ${ }^{34}$ To ensure successful treatment, monitoring of patients on antiretroviral therapy (ART) should start from the day of initiation. ${ }^{56}$ The WHO immunological criteria for monitoring of response to ART have low sensitivity and positive predictive value in detecting treatment failure. Therefore, relying on CD4 counts for treatment monitoring would lead to misclassifications of treatment failure, which could result in unnecessary or delayed switch to second-line ART. ${ }^{6}$ Viral load monitoring is important to avoid these misclassifications, the problem of switching to second-line ART and the risk of drug resistance. ${ }^{78}$ Monitoring the level of HIV RNA to confirm appropriate response to treatment and durable viral suppression is the most accurate and meaningful measure of ART effectiveness. ${ }^{9}$ It is the 
gold standard for identification of treatment failure in patients on ART, and since 2013 WHO has recommended it as the preferred monitoring approach to diagnose and confirm antiretroviral (ARV) treatment failure. Viral load should be monitored routinely at 6 months, at 12 months and every 12 months thereafter. ${ }^{5810}$ Virological failure is defined by a persistently detectable viral load exceeding 1000 copies/mL (ie, two consecutive viral load measurements within a 3-month interval, with adherence support between measurements) after at least 6 months of starting a new ART regimen. ${ }^{6}$ Virological failure can occur for many reasons, such as patient adherence-related factors (missed clinic appointments, high pill burden and/or dosing frequency) and regimen-related factors (suboptimal pharmacokinetics, reduced efficacy due to prior exposure to suboptimal regimens). ${ }^{11}$

Increasing and monitoring the capacity for viral load testing are important measures for the global control of HIV, particularly in Sub-Saharan Africa, which has the highest prevalence of HIV worldwide. ${ }^{12}$ Studies suggest that around $70 \%$ of patients on first-line ART who have a first high viral load will be virally suppressed following an adherence intervention, indicating non-adherence as the reason for the high viral load in majority of cases. ${ }^{6}$ The UNAIDS (Joint United Nations Programme on HIV and AIDS) targets that $90 \%$ of people receiving ART would be virally suppressed by $2020 .{ }^{13}$ However, surveys reveal that only $32.4 \%$ of people living with HIV (PLHIV) have viral suppression. ${ }^{14}$ Currently, in Ethiopia, $1.5 \%$ of patients are on second-line ART regimens due to first-line treatment failure. ${ }^{15}$ According to a study in Felegehiwot Referral Hospital in Amhara Region, since HAART was started, $51.1 \%$ of study participants have encountered virological failure within 6-48 months. ${ }^{16}$ The prevalence of virological failure was $11.5 \%$ and $10.7 \%$ in studies conducted in Tigray and Amhara regions, respectively. ${ }^{16} 17$

Previously, targeted virological testing was adopted in Ethiopia for ART clients who have failed clinically and immunologically. However, following WHO recommendation, routine viral load testing has been practised since 2016. Currently, a significant number of clients have been experiencing virological failure and have switched to second-line treatment. Additionally, in 2018, viral load testing was integrated as one of ten weekly reportable diseases/events in Amhara Public Health Institute. Despite all these, the reasons for virological failure remain unclear. $^{5}$ Existing studies were conducted before the launch of routine viral load testing, and therefore have not explored the current situation of existing routine viral load testing. ${ }^{17} 18$ Taking consecutive viral load measurements would be a better strategy to determine virological failure, compared with a single measurement which may lead to misclassification of HIV treatment failure. ${ }^{19}$ However, previous studies took only a single virological test to identify virological failure. Hence, addressing this knowledge gap will help healthcare providers, local administrators, public health planners, policymakers and partners to plan and design appropriate intervention strategies. Patients who are at risk for virological failure can be identified early and prevention strategies can be implemented accordingly. In turn patients will get quality service and care, resulting in sustained HIV viral suppression and contributing to restoring their immune function with improvements in clinical well-being and reducing mortality and HIV transmission at the community level.

\section{METHODS AND MATERIALS Study area and period}

The town of Kombolcha is one of the 21 districts in South Wollo Zone in Amhara Region. It is $23 \mathrm{~km}$ away from the zonal town of Dessie, $503 \mathrm{~km}$ from Bahir Dar and 377 $\mathrm{km}$ from Addis Ababa. There are six health posts, four government health centres and ten private clinics, with two health centres providing ART service. According to the information obtained from ART clinics in November 2018, about 7178 PLHIV were ever enrolled in ART care. Out of these, 5327 ever started ART and 4128 were currently on HAART. The study was conducted from April to May 2019.

\section{Study design and population}

An institution-based, unmatched, case-control study was conducted. The study population consisted of all adults living with HIV on first-line ART for 6 months or more before the first viral load test, followed at public health facilities in the town of Kombolcha and had their viral load tested from October 2016 to October 2018. All adults living with HIV on first-line ART for 6 months or more before the first viral load test who had documented viral load test results of $>1000$ copies $/ \mathrm{mL}$ with two consecutive measurements in a 3-month interval were included as cases, whereas those who had documented viral load test results of $\leq 1000$ copies/mL were included as controls. Similarly, adults living with HIV on first-line ART for 6 months or more before the first viral load test whose one or both test results were not documented on the high viral load register were excluded from the cases, whereas test results that were not documented on routine viral load register were excluded from the controls.

\section{Study variables}

Virological failure was the outcome variable of this study. Sociodemographic characteristics (age, sex, residency, educational level, occupation, marital status and religion), clinical and behavioural factors (nutritional status, functional status, WHO clinical stage, presence of Opportunistic Infections (OIs) and disclosure status), drugrelated factors (original first-line ART regimen, change of ARV regimen or individual drug, current ART regimen at the time of viral load test, adherence, duration on ART, cotrimoxazole preventive therapy use, frequency of ART treatment per day and dispensed dose (number of pills) per day), and haematological factors (haemoglobin and CD4 count) were predictor variables. 


\section{Sample size determination}

Sample size was determined using Epi Info V.7 StatCalc. The assumptions made for the sample size calculation were $95 \%$ CI, $80 \%$ power and a case to control ratio of $1: 2$. Sample size was calculated by taking the key predictor of virological failure (immunological failure) from a previous study. ${ }^{16}$ Therefore, the calculated sample size was 353 (118 cases and 235 controls). To compensate for those with incomplete records, $10 \%$ was added to the calculated sample size. Therefore the final calculated sample size came at 389 (130 cases and 259 controls), all of which participated in the study.

\section{Sampling methods and procedures}

Two health centres provide ART treatment and care services in the town of Kombolcha. From these health centres, all medical record numbers of clients who had tested for viral load from October 2016 to October 2018 were taken from routine and high viral load registers as virologically suppressed and failed, using code for both health centres. About 1919 HIV-infected adults who had suppressed viral load and 135 virologically failed adults living with HIV had switched to a second-line regimen. From virologically failed clients 130 cases and from all virologically suppressed clients 259 controls were selected using a computer-generated simple random sampling method. Finally a total of 389 clients were included in the study.

\section{Data collection tools and procedures}

Data were extracted from the charts of patients using a structured checklist. All available data from patient intake forms, WHO patient follow-up charts and viral load test registers containing detailed information on patients were reviewed for the selected cases and controls. Sociodemographic characteristics and clinical and laboratory data (haemoglobin and $\mathrm{CD}_{4}^{+}$count) were collected from the chart of each study participant. Data were collected by four ART trained health professionals with one supervisor.

\section{Data quality assurance}

Before starting the actual data collection, 1-day training was given to the data collectors and the supervisor. The checklist was reviewed and checked for completeness by the supervisor and the principal investigator. The principal investigator and the supervisor closely monitored the whole data collection process daily, with the provision of necessary feedback.

\section{Data processing and analysis}

Data were checked for completeness, entered into Epi Info V.7, cleaned and exported to SPSS V.20 for analysis. For descriptive statistics, frequencies were used to describe the demographic, clinical, medication and haematological characteristics of patients. Bivariable logistic regression was carried out for all independent variables with an outcome variable. To identify candidate variables for multivariable logistic regression analysis, factors with $\mathrm{p}<0.2$ at bivariable logistic regression analysis were selected. Hosmer-Lemeshow goodness of fit test was used to check the model. Finally, independent variables that have a significant association with virological failure were identified based on adjusted OR (AOR), 95\% CI and $\mathrm{p}<0.05$.

\section{Patient and public involvement}

There were no patients involved in this study.

\section{RESULTS}

\section{Sociodemographic characteristics}

A total of 389 participants (130 cases and 259 controls) were included in the study. The mean age of cases and controls was 31.6 years $(\mathrm{SD} \pm 10.72)$ and 36.6 years (SD $\pm 9.48)$, respectively. Seventy-nine $(60.8 \%)$ and 160 $(61.8 \%)$ cases and controls were women. Ninety-nine $(76.2 \%)$ and $170(65.6 \%)$ cases and controls follow Muslim religion, respectively. Ninety-nine $(76.2 \%)$ cases and $203(78.4 \%)$ controls were living in rural areas. Fifty-one $(39.2 \%)$ cases and $130(50.2 \%)$ controls were married. Sixty-four (49.2\%) cases and 121 (46.7\%) controls attended primary education. Fifty-one (39.2\%) and $75(29 \%)$ cases and controls were not employed (table 1).

\section{Clinical and behavioural characteristics}

Among 389 participants (130 cases and 259 controls), $74(56.9 \%)$ cases and $226(87.3 \%)$ controls disclosed their HIV status to their families. One hundred and four $(80 \%)$ cases and $242(93.4 \%)$ controls had working functional status. Moreover $55(42.3 \%)$ and $72(27.8 \%)$ cases and controls had WHO stage III and IV at baseline, respectively. Fifty $(38.5 \%)$ cases and $64(24.7 \%)$ controls had undernutrition at baseline. Ninety-two $(70.8 \%)$ and $109(42.1 \%)$ cases and controls had missed their clinic visit in the last 6 months before the viral load test. Twentyeight $(21.5 \%)$ cases and $25(9.7 \%)$ controls experienced opportunistic infections during the last 6 months of their treatment period (table 2).

\section{Antiretroviral drug and haematological characteristics}

While $47(36.2 \%)$ cases started their ART treatment with stavudine (D4T)-based regimen, 130 (50.2\%) controls were on TDF-based regimen. Fifty-seven $(43.8 \%)$ and $94(36.3 \%)$ cases and controls changed their original regimen, respectively. Eighty-nine $(68.5 \%)$ cases and 131 (50.6) controls take their treatment twice daily. Ninetynine $(76.2 \%)$ cases and $201(77.6 \%)$ controls were on ART for 48 months and more. Moreover 25 (19.2\%) and $28(10.8 \%)$ cases and controls had poor adherence to treatment, respectively. The baseline CD4 count of 94 $(72.3 \%)$ cases and $150(57.9 \%)$ controls was $\leq 250$ cells/ $\mathrm{mm}^{3}$. Similarly $66(50.8 \%)$ and $55(21.2 \%)$ cases and controls had a CD 4 count of $\leq 250$ cells $/ \mathrm{mm}^{3}$ at the time of the viral load test, respectively. Fifty-eight $(44.6 \%)$ cases and $74(28.6 \%)$ controls had baseline haemoglobin of $<12 \mathrm{~g} / \mathrm{dL}$ (table 3 ). 
Table 1 Sociodemographic characteristics of HIV-infected patients on first-line HAART at Kombolcha town health facilities, 2019

\begin{tabular}{|c|c|c|}
\hline Variables & Case, n (\%) & Control, n (\%) \\
\hline \multicolumn{3}{|l|}{ Sex } \\
\hline Male & $51(39.2)$ & 99 (38.2) \\
\hline Female & $79(60.8)$ & $160(61.8)$ \\
\hline \multicolumn{3}{|l|}{ Age } \\
\hline$<35$ years & $79(60.8)$ & $105(40.5)$ \\
\hline$\geq 35$ years & $51(39.2)$ & $154(59.5)$ \\
\hline \multicolumn{3}{|l|}{ Religion } \\
\hline Muslim & 99 (76.2) & $170(65.6)$ \\
\hline Others & $31(23.8)$ & $89(34.4)$ \\
\hline \multicolumn{3}{|l|}{ Residency } \\
\hline Rural & 99 (76.2) & $203(78.4)$ \\
\hline Urban & $31(23.8)$ & $56(21.6)$ \\
\hline \multicolumn{3}{|l|}{ Marital status } \\
\hline Married & $51(39.2)$ & $130(50.2)$ \\
\hline Never married & $41(31.5)$ & $62(23.9)$ \\
\hline Divorced/separated & $32(24.6)$ & $42(16.2)$ \\
\hline Widowed & $6(4.6)$ & $25(9.7)$ \\
\hline \multicolumn{3}{|l|}{ Level of education } \\
\hline Not educated & $53(40.8)$ & $84(32.4)$ \\
\hline Primary & $64(49.2)$ & $121(46.7)$ \\
\hline Secondary/tertiary & $13(10)$ & $54(20.8)$ \\
\hline \multicolumn{3}{|l|}{ Occupation } \\
\hline Government employee & $8(6.2)$ & $41(15.8)$ \\
\hline Not employed & $51(39.2)$ & $75(29)$ \\
\hline Farmer & $39(30)$ & $40(15.4)$ \\
\hline Daily labourer & $18(13.8)$ & $48(18.5)$ \\
\hline Housewife & $5(3.8)$ & $30(11.6)$ \\
\hline Others & $9(6.9)$ & $25(9.7)$ \\
\hline \multicolumn{3}{|l|}{ Level of education } \\
\hline No education & $53(40.8)$ & $84(32.4)$ \\
\hline Primary & $64(49.2)$ & $121(46.7)$ \\
\hline Secondary/tertiary & $13(10)$ & $54(20.8)$ \\
\hline
\end{tabular}

HAART, highly active antiretroviral therapy.

\section{Determinants of HIV virological failure}

After adjustment for possible effects of confounding variables, age, marital status, occupation, disclosure status, baseline functional status, missed clinic visit, current ART regimen, adherence to treatment and recent CD4 count were found significantly associated with virological failure.

The odds of HIV virological failure were 2.4-fold (AOR=2.44, 95\% CI 1.353 to 4.411) higher in clients aged less than 35 years compared with older counterparts. The odds of virological failure in clients who had divorced or separated from their spouses were threefold $(\mathrm{AOR}=3.03$,
Table 2 Clinical and behavioural characteristics of HIVinfected patients on first-line HAART at Kombolcha town health facilities, 2019

\begin{tabular}{|c|c|c|}
\hline Variables & Case, n (\%) & Control, n (\%) \\
\hline \multicolumn{3}{|l|}{ Disclosure status } \\
\hline Yes & $74(56.9)$ & $226(87.3)$ \\
\hline No & $56(43.1)$ & $33(12.7)$ \\
\hline \multicolumn{3}{|l|}{ Baseline functional status } \\
\hline Working & $104(80)$ & $242(93.4)$ \\
\hline Ambulatory & $26(20)$ & $17(6.6)$ \\
\hline \multicolumn{3}{|l|}{ Current functional status } \\
\hline Working & $123(94.6)$ & $253(97.7)$ \\
\hline Ambulatory & $7(5.4)$ & $6(2.3)$ \\
\hline \multicolumn{3}{|l|}{ Baseline WHO stage } \\
\hline Stage I and II & 75 (57.7) & $187(72.2)$ \\
\hline Stage III and IV & 55 (42.3) & $72(27.8)$ \\
\hline \multicolumn{3}{|l|}{ Current WHO stage } \\
\hline T stage I and II & $123(94.6)$ & $250(96.5)$ \\
\hline T stage III and IV & $7(5.4)$ & $9(3.5)$ \\
\hline \multicolumn{3}{|l|}{ Baseline nutritional status } \\
\hline No undernutrition & $80(61.5)$ & $195(75.3)$ \\
\hline Undernutrition & $50(38.5)$ & $64(24.7)$ \\
\hline \multicolumn{3}{|l|}{ Current nutritional status } \\
\hline No undernutrition & $98(75.4)$ & $231(89.2)$ \\
\hline Undernutrition & 32 (24.6) & $28(10.8)$ \\
\hline \multicolumn{3}{|c|}{ Missed clinic visit in the last 6 months } \\
\hline Yes & $92(70.8)$ & $109(42.1)$ \\
\hline No & $38(29.2)$ & $150(57.9)$ \\
\hline \multicolumn{3}{|c|}{ Number of missed clinic visits } \\
\hline Once & $14(15.2)$ & $40(36.7)$ \\
\hline Twice or more & $78(84.8)$ & $69(63.3)$ \\
\hline \multicolumn{3}{|l|}{ Time of missed clinic } \\
\hline In the last 3 months & 49 (53.3) & $61(56)$ \\
\hline In the last 3-6 months & $43(46.7)$ & $48(44)$ \\
\hline \multicolumn{3}{|l|}{ History of Ols } \\
\hline Yes & $28(21.5)$ & $25(9.7)$ \\
\hline No & $102(78.5)$ & $234(90.3)$ \\
\hline
\end{tabular}

HAART, highly active antiretroviral therapy; Ols, opportunistic infections.

$95 \%$ CI 1.356 to 6.778 ) higher than of married clients. The odds of HIV virological failure were 4.7-fold (AOR $=4.69$, $95 \%$ CI 1.536 to 14.292$)$ and eightfold (AOR $=8.04,95 \%$ CI 2.532 to 25.558 ) higher in clients who were not employed and farmers in occupation compared with governmentemployed clients, respectively.

The odds of virological failure were fivefold $(\mathrm{AOR}=5.00$, 95\% CI 2.596 to 9.630 ) higher in clients who did not disclose their HIV status compared with those who disclosed. Similarly the odds of virological failure were 
Table 3 Antiretroviral drug and haematological characteristics of HIV-infected patients on first-line HAART at Kombolcha town health facilities, 2019

\begin{tabular}{|c|c|c|}
\hline Variables & Case, n (\%) & Control, n (\%) \\
\hline \multicolumn{3}{|l|}{ Original ART regimen } \\
\hline D4T-based & $47(36.2)$ & $76(29.3)$ \\
\hline ZDV-based & $40(30.8)$ & $53(20.5)$ \\
\hline TDF-based & $43(33.1)$ & $130(50.2)$ \\
\hline \multicolumn{3}{|l|}{ Change of ART } \\
\hline Yes & $57(43.8)$ & $94(36.3)$ \\
\hline No & $73(56.2)$ & $165(63.7)$ \\
\hline \multicolumn{3}{|c|}{ Number of changes in ART } \\
\hline Once & $50(87.7)$ & $84(89.4)$ \\
\hline Twice or more & $7(12.3)$ & $10(10.6)$ \\
\hline \multicolumn{3}{|c|}{ Current ART regimen at the time of the VL test } \\
\hline ZDV-based & $62(47.7)$ & $71(27.4)$ \\
\hline TDF-based & $68(52.3)$ & $188(72.6)$ \\
\hline \multicolumn{3}{|c|}{ Frequency of treatment } \\
\hline Once a day & $41(31.5)$ & $128(49.4)$ \\
\hline Twice a day & $89(68.5)$ & $131(50.6)$ \\
\hline \multicolumn{3}{|l|}{ Number of ART pills } \\
\hline One pill per day & $40(30.8)$ & $128(49.4)$ \\
\hline Two pills per day & $45(34.6)$ & $51(19.7)$ \\
\hline Three pills per day & $45(34.6)$ & $80(30.9)$ \\
\hline \multicolumn{3}{|l|}{ Adherence } \\
\hline Good & $105(80.8)$ & $231(89.2)$ \\
\hline Poor & $25(19.2)$ & $28(10.8)$ \\
\hline \multicolumn{3}{|l|}{ Duration on ART } \\
\hline $6-23$ months & $9(6.9)$ & $13(5)$ \\
\hline 24-47 months & $22(16.9)$ & $45(17.4)$ \\
\hline$\geq 48$ months & $99(76.2)$ & $201(77.6)$ \\
\hline \multicolumn{3}{|c|}{ Current CPT use during VL test } \\
\hline Yes & $41(31.5)$ & $58(22.4)$ \\
\hline No & $89(68.5)$ & $201(77.6)$ \\
\hline \multicolumn{3}{|l|}{ Baseline CD4 count } \\
\hline$\leq 250$ cells $/ \mathrm{mm}^{3}$ & $94(72.3)$ & $150(57.9)$ \\
\hline$>250$ cells $/ \mathrm{mm}^{3}$ & $36(27.7)$ & $109(42.1)$ \\
\hline \multicolumn{3}{|l|}{ Recent CD4 count } \\
\hline$\leq 250$ cells $/ \mathrm{mm}^{3}$ & $66(50.8)$ & 55 (21.2) \\
\hline$>250$ cells $/ \mathrm{mm}^{3}$ & $64(49.2)$ & $204(78.8)$ \\
\hline \multicolumn{3}{|l|}{ Baseline Hgb } \\
\hline$<12 \mathrm{~g} / \mathrm{dL}$ & $58(44.6)$ & $74(28.6)$ \\
\hline$\geq 12 \mathrm{~g} / \mathrm{dL}$ & $72(55.4)$ & $185(71.4)$ \\
\hline \multicolumn{3}{|l|}{ Recent Hgb } \\
\hline$<12 \mathrm{~g} / \mathrm{dL}$ & $40(30.8)$ & $45(17.4)$ \\
\hline$\geq 12 \mathrm{~g} / \mathrm{dL}$ & $90(69.2)$ & 214 (82.6) \\
\hline
\end{tabular}

ART, antiretroviral therapy; CPT, cotrimoxazole preventive therapy; D4T, Stavudine; HAART, highly active antiretroviral therapy; Hgb, haemoglobin; TDF, tenofovir; ZDV, Zidovudine. 2.7-fold (AOR=2.71, 95\% CI 1.148 to 6.392$)$ higher in clients who had ambulatory functional status at baseline compared with those who had working functional status. Moreover the odds of virological failure were 4.5-fold (AOR $=4.512,95 \%$ CI 2.438 to 8.350 ) higher in clients who had missed their clinic visit in the last 6 months before the viral load test compared with those who did not miss their clinic visit.

The odds of virological failure were threefold (AOR=2.99, 95\% CI 1.333 to 6.734 ) higher in clients who had poor adherence to ART than those who had good adherence. Similarly the odds of virological failure were 2.6-fold (AOR=2.633, 95\% CI 1.444 to 4.800) higher among clients who were on Zidovudine (ZDV)- based regimen during the viral load test than those who were on TDF-based regimen.

The odds of virological failure were 7.5-fold (AOR=7.51, $95 \%$ CI 3.985 to 14.140 ) higher in clients who had a recent CD4 count of $\leq 250$ cells $/ \mathrm{mm}^{3}$ compared with those with $>250$ cells $/ \mathrm{mm}^{3}$ (table 4 ).

\section{DISCUSSION}

In this study virological failure was found to be significantly associated with age, marital status, occupation, disclosure status, baseline functional status, missed clinic visit, current ART regimen, adherence to treatment and recent $\mathrm{CD} 4$ count.

The odds of HIV virological failure were 2.4-fold higher in clients aged less than 35 years compared with older clients. This finding is similar to studies conducted in Tigray, ${ }^{17}$ Gondar, ${ }^{18}$ Uganda, ${ }^{20}$ Mozambique,${ }^{21}$ Australia $^{22}$ and Latin America, ${ }^{23}$ where younger patients had a higher risk of virological failure. This might be due to their vulnerability to emotional instability with depression, which leads to poor adherence resulting in poor treatment outcomes. ${ }^{24}$ The odds of virological failure were threefold higher in clients who had divorced or separated from their spouses compared with those of married clients. The increased risk of virological failure might be due to failure to get care and support from her/ his spouse in taking treatment and follow-up. However, a study conducted in Myanmar revealed that patients who were divorced or separated from their spouses had a significantly lower risk of failure. ${ }^{25}$ The difference in findings might be due to the use of different viral load cut-off points for classification of virological failure. The odds of HIV virological failure were 4.7-fold and eightfold higher in clients who were not employed and farmers in occupation compared with government-employed clients, respectively. This finding is in line with the findings from China. ${ }^{26}$ This might be due to differences in lifestyle, awareness of follow-up and drug-taking time, which could affect their adherence to treatment.

Clients should be counselled and encouraged to disclose their status to their sexual partners and others, to participate in peer support groups or to be a member of PLHIV associations. ${ }^{5}$ This study showed that the odds 
Table 4 Simple and multiple binary logistic regression analyses for determinants of virological failure among HIV-infected adults on HAART at Kombolcha town public health facilities, 2019

\begin{tabular}{|c|c|c|c|c|}
\hline \multirow[b]{2}{*}{ Variables } & \multicolumn{2}{|c|}{ Virological failure } & \multirow[b]{2}{*}{ COR (95\% Cl) } & \multirow[b]{2}{*}{ AOR $(95 \% \mathrm{Cl})$} \\
\hline & Case, n (\%) & Control, n (\%) & & \\
\hline \multicolumn{5}{|l|}{ Age } \\
\hline$<35$ years & $79(60.8)$ & $105(40.5)$ & 2.272 (1.477 to 3.495$)$ & $2.442(1.353 \text { to } 4.411)^{\star}$ \\
\hline$\geq 35$ years & $51(39.2)$ & $154(59.5)$ & 1 & 1 \\
\hline \multicolumn{5}{|l|}{ Religion } \\
\hline Muslim & 99 (76.2) & $170(65.6)$ & 1.672 (1.037 to 2.697$)$ & 1.153 (0.580 to 2.293$)$ \\
\hline Orthodox & $31(23.8)$ & $89(34.4)$ & 1 & 1 \\
\hline \multicolumn{5}{|l|}{ Marital status } \\
\hline Married & $51(39.2)$ & $130(50.2)$ & 1 & 1 \\
\hline Never married & $41(31.5)$ & 62 (23.9) & 1.686 (1.012 to 2.808$)$ & 1.518 (0.767 to 3.002$)$ \\
\hline Divorced/separated & $32(24.6)$ & $42(16.2)$ & 1.942 (1.107 to 3.408$)$ & $3.032(1.356 \text { to } 6.778)^{*}$ \\
\hline Widowed & $6(4.6)$ & $25(9.5)$ & 0.612 (0.237 to 1.579$)$ & 0.430 (0.128 to 1.442$)$ \\
\hline \multicolumn{5}{|l|}{ Level of education } \\
\hline Not educated & $53(40.8)$ & $84(32.4)$ & 2.621 (1.306 to 5.258$)$ & 2.594 (0.916 to 7.349 ) \\
\hline Primary & $64(49.2)$ & $121(46.7)$ & 2.197 (1.116 to 4.324$)$ & 2.078 (0.766 to 5.640$)$ \\
\hline Secondary/tertiary & $13(10)$ & $54(20.8)$ & 1 & 1 \\
\hline \multicolumn{5}{|l|}{ Occupation } \\
\hline Government employee & $8(6.2)$ & $41(15.8)$ & 1 & 1 \\
\hline Unemployed & $51(39.2)$ & $75(29.0)$ & 3.485 (1.509 to 8.048 ) & 4.686 (1.536 to 14.292$)^{\star}$ \\
\hline Farmer & $39(30.0)$ & $40(15.4)$ & 4.997 (2.080 to 12.006$)$ & $8.044(2.532 \text { to } 25.558)^{*}$ \\
\hline Daily labourer & $18(13.8)$ & $48(18.5)$ & 1.922 (0.757 to 4.877$)$ & 1.929 (0.572 to 6.503$)$ \\
\hline Housewife & $5(3.8)$ & $30(11.6)$ & 0.854 (0.254 to 2.872$)$ & 1.333 (0.296 to 6.010$)$ \\
\hline Others & $9(6.9)$ & $25(9.7)$ & 1.845 (0.630 to 5.403$)$ & 2.869 (0.735 to 11.207$)$ \\
\hline \multicolumn{5}{|l|}{ Disclosure status } \\
\hline No & $56(43.1)$ & $33(12.7)$ & 5.183 (3.131 to 8.578$)$ & 5.000 (2.596 to 9.630$)^{\star}$ \\
\hline Yes & $74(56.9)$ & $226(87.3)$ & 1 & 1 \\
\hline \multicolumn{5}{|l|}{ Baseline functional status } \\
\hline Ambulatory & $26(20)$ & $17(6.6)$ & 3.559 (1.852 to 6.838$)$ & $2.709(1.148 \text { to } 6.392)^{\star}$ \\
\hline Working & 104(80) & $242(93.4)$ & 1 & 1 \\
\hline \multicolumn{5}{|l|}{ Baseline WHO stage } \\
\hline Stage III and IV & $55(42.3)$ & $72(27.8)$ & 1.905 (1.225 to 2.962$)$ & 1.350 (0.713 to 2.556$)$ \\
\hline Stage I and II & $75(57.7)$ & $187(72.2)$ & 1 & 1 \\
\hline \multicolumn{5}{|l|}{ Current nutritional status } \\
\hline Acute undernutrition & $32(24.6)$ & $28(10.8)$ & 2.694 (1.539 to 4.714$)$ & $1.391(0.602$ to 3.211$)$ \\
\hline No acute undernutrition & $98(75.4)$ & $231(89.2)$ & 1 & 1 \\
\hline \multicolumn{5}{|c|}{ Missed clinic visit in the last 6 months } \\
\hline Yes & $92(70.8)$ & $109(42.1)$ & 3.332 (2.122 to 5.232$)$ & $4.512(2.438 \text { to } 8.350)^{\star}$ \\
\hline No & $38(29.2)$ & $150(57.9)$ & 1 & 1 \\
\hline \multicolumn{5}{|c|}{ History of Ols in the last 6 months } \\
\hline Yes & $28(21.5)$ & $25(9.7)$ & 2.569 (1.428 to 4.623$)$ & 1.279 (0.512 to 3.195$)$ \\
\hline No & $102(78.5)$ & $234(90.3)$ & 1 & 1 \\
\hline \multicolumn{5}{|l|}{ Original ART regimen } \\
\hline D4T-based & 47 (36.2) & 76 (29.3) & 1.870 (1.133 to 3.086$)$ & 1.366 (0.546 to 3.419$)$ \\
\hline ZDV-based & $40(30.8)$ & $53(20.5)$ & 2.282 (1.335 to 3.900$)$ & 0.983 (0.315 to 3.066$)$ \\
\hline
\end{tabular}


Table 4 Continued

\begin{tabular}{|c|c|c|c|c|}
\hline \multirow[b]{2}{*}{ Variables } & \multicolumn{2}{|c|}{ Virological failure } & \multirow[b]{2}{*}{ COR $(95 \% \mathrm{Cl})$} & \multirow[b]{2}{*}{ AOR $(95 \% \mathrm{Cl})$} \\
\hline & Case, n (\%) & Control, n (\%) & & \\
\hline TDF-based & $43(33.1)$ & $130(50.2)$ & 1 & 1 \\
\hline \multicolumn{5}{|c|}{ Current ART regimen at the time of the VL test } \\
\hline ZDV-based & $62(47.7)$ & $71(27.4)$ & 2.341 (1.508 to 3.633$)$ & 2.633 (1.444 to 4.800$)^{*}$ \\
\hline TDF-based & $68(52.3)$ & $188(72.6)$ & 1 & 1 \\
\hline \multicolumn{5}{|l|}{ Frequency of treatment } \\
\hline Twice per day & $89(68.5)$ & $131(50.6)$ & 2.121 (1.362 to 3.303$)$ & 1.013 (0.031 to 33.261$)$ \\
\hline Once per day & $41(31.5)$ & $128(49.4)$ & 1 & 1 \\
\hline \multicolumn{5}{|l|}{ Number of ART pills } \\
\hline One pill per day & $40(30.8)$ & $128(49.4)$ & 1 & 1 \\
\hline Two pills per day & $45(34.6)$ & $51(19.7)$ & 2.824 (1.653 to 4.823$)$ & 0.988 (0.026 to 37.997$)$ \\
\hline Three pills per day & $45(34.6)$ & $80(30.9)$ & 1.800 (1.082 to 2.996$)$ & $1.220(0.035$ to 42.729$)$ \\
\hline \multicolumn{5}{|l|}{ Adherence } \\
\hline Poor & $25(19.2)$ & $28(10.8)$ & 1.964 (1.093 to 3.531$)$ & $2.996(1.333 \text { to } 6.734)^{*}$ \\
\hline Good & $105(80.8)$ & 231 (89.2) & 1 & 1 \\
\hline \multicolumn{5}{|l|}{ Recent CD4 count } \\
\hline$\leq 250$ cells $/ \mathrm{mm}^{3}$ & $66(50.8)$ & $55(21.2)$ & 3.825 (2.427 to 6.028$)$ & 7.507 (3.985 to 14.140$)^{\star}$ \\
\hline$>250$ cells $/ \mathrm{mm}^{3}$ & $64(49.2)$ & $204(78.8)$ & 1 & 1 \\
\hline \multicolumn{5}{|l|}{ Recent Hgb } \\
\hline$<12 \mathrm{~g} / \mathrm{dL}$ & $40(30.8)$ & $45(17.4)$ & 2.114 (1.292 to 3.457$)$ & 1.302 (0.653 to 2.596$)$ \\
\hline$\geq 12 \mathrm{~g} / \mathrm{dL}$ & $90(69.2)$ & $214(82.6)$ & 1 & \\
\hline
\end{tabular}

The $p$ value for Hosmer-Lemeshow goodness of fit test was found to be 0.087 .

*Variables with significant association during multiple binary logistic regression analysis.

AOR, adjusted OR; ART, antiretroviral therapy; COP, country operational plan; D4T, stavudine; HAART, highly active antiretroviral therapy; Hgb, haemoglobin; Ols, opportunistic infections; TDF, tenofovir; VL, viral load; ZDV, zidovudine.

of virological failure were fivefold higher in clients who did not disclose their HIV status to their families, compared with those who disclosed their HIV status. This finding agrees with the findings from Nigeria ${ }^{27}$ and Tanzania, ${ }^{28}$ which showed non-disclosure of HIV status increased the odds of virological failure. This might be due to failure in getting help or adherence support from families or PLHIV associations and the difficulty of taking their treatment on time. ${ }^{5}$ Similarly the odds of virological failure were 2.7 -fold higher in clients who had ambulatory functional status at baseline compared with those who had working functional status. This finding agrees with the findings from Bahir Dar $^{16}$ and Bale Zone, ${ }^{29}$ where being ambulatory at baseline was found to be a significant risk factor for virological failure. Since patients' ability to perform routine activities related to advanced HIV disease and opportunistic infections, virological failure might be due to delayed start of treatment when the disease has progressed with high viral load or due to difficulty in properly attending follow-up. ${ }^{30}$ Moreover, the odds of virological failure were 4.5 -fold higher in clients who missed their clinic visit in the last 6 months before the viral load test, compared with those who did not miss their clinic visit. This finding is supported by the findings from Australia ${ }^{22}$ and Myanmar, ${ }^{25}$ where virological failure was associated with missed clinic appointments. This finding might be due to patients on ART missing their appointments and therefore more likely to miss their doses, resulting in poor adherence to treatment.

Treatment goals should be maximal and durable suppression of viral load, restoration and preservation of immunological function, improvement of quality of life, and reduction of HIV-related morbidity and mortality. ${ }^{5}{ }^{19}$ Rates of viral load decline towards undetectable are influenced by clients' adherence to the regimen. ${ }^{19}$ This study showed that the odds of virological failure were threefold higher in clients who had poor adherence to ART compared with those who had good adherence. Similarly, studies conducted in Tigray, ${ }^{17}$ Gondar, ${ }^{18}$ Bahir Dar, ${ }^{16}$ Mozambique ${ }^{17}$ Nigeria, ${ }^{13}$ Uganda ${ }^{21}$ and Tanzania ${ }^{25}$ showed that poor adherence increased the odds of virological failure. This might be because poor adherence could allow periods of viral replication, leading to the development of drug resistance and resulting in limited treatment effectiveness. ${ }^{31}$ Predictors of virological success also depend on high potency, tolerability and convenience of the ARV regimen. ${ }^{31}$ 
This study revealed that the odds of HIV virological failure were 2.6-fold higher in clients with ZDV-based regimen during the viral load test, compared with those who were on TDF-based regimen. This finding is in line with findings from a meta-analysis conducted in Ethiopia which showed superior viral load suppression of using TDF-based first-line regimen than ZDV-based regimen. ${ }^{32}$ This might be because TDF-based regimens were more likely to be tolerated than ZDV-based regimens. ${ }^{32}$ This might also be due to the high efficacy and lower level of toxicity of fixed-dose TDF-3TC compared with fixed-dose ZDV-3TC. ${ }^{33}$ The 2018 Ethiopian consolidated ART guideline recommends the more tolerable DTG-based regimen for first-line therapy, which can improve adherence to treatment. ${ }^{4}$

The odds of virological failure were 7.5-fold higher in clients who had a recent CD4 count of $\leq 250$ cells $/ \mathrm{mm}^{3}$ compared with those with $>250$ cells $/ \mathrm{mm}^{3}$. This finding is in line with findings from Bahir Dar, ${ }^{16}$ Tigray, ${ }^{17}$ France, ${ }^{34}$ Brazil ${ }^{35}$ Australia ${ }^{22}$ and China. ${ }^{26}$ This might be because a significant number of CD4 cells can respond to HIV antigens present on the surface of infected cells, which is associated with lower HIV viral loads, resulting in viral control. $^{36}$

Since taking consecutive viral load measurements would be a better strategy to determine virological failure, compared with a single measurement, this study takes two consecutive viral load measurements, which avoid misclassification of HIV treatment failure. Since it was conducted at the health centre level, virologically failed clients were referred to different hospitals for a secondline regimen, which created difficulty in including primary data from clients. Despite the recommendation of DTG-based regimen for first-line therapy, its use has not started during the study period and was therefore not considered.

\section{CONCLUSIONS AND RECOMMENDATIONS}

This study revealed that age, marital status, occupation, disclosure status, baseline functional status, missed clinic visit, current ART regimen, adherence to treatment and recent CD4 count were significantly associated with virological failure. Therefore, implementation of treatment and care strategies should consider younger clients, unemployed clients, farmers and divorced/separated clients to improve their treatment follow-up for better viral suppression. Adherence support should also be strengthened for clients who had poor adherence, and those who miss their clinic visits should be targeted to help them better adhere to treatment, and therefore help them boost their immunity and suppress viral replication. In addition to these, clients should be encouraged to disclose their HIV infection status to their families or supportive associations as this will help them get support. Chronic care and follow-up should also be strengthened by focusing on ambulatory clients at the start of their
HAART, clients who have been taking ZDV-based regimens and clients with recent lower CD4 count.

Acknowledgements The authors acknowledge the Bahir Dar University and would like to send their gratitude to all data collectors.

Contributors All authors (HMM, ZMN, AA, KM) contributed equally, from topic selection to manuscript preparation.

Funding The authors have not declared a specific grant for this research from any funding agency in the public, commercial or not-for-profit sectors.

Competing interests None declared.

Patient consent for publication Not required.

Ethics approval Ethical approval was obtained from Bahir Dar University College of Medicine and Health Institutional Review Board. Written permission to conduct the study was granted by the Bahir Dar University. The Kombolcha town administration health office wrote supporting letters for the respective health centres. This study was a retrospective follow-up; patient records were anonymised and de-identified before analysis. The confidentiality of information obtained from each study participant's medical records was guaranteed by omitting names or any personal identifiers. Data accessibility to a third party was limited by keeping the collected data safe throughout the whole process of the research activity. Patient informed consent was not required as only anonymous and operational monitoring data were collected and analysed.

Provenance and peer review Not commissioned; externally peer reviewed.

Data availability statement Data can be shared on request.

Open access This is an open access article distributed in accordance with the Creative Commons Attribution Non Commercial (CC BY-NC 4.0) license, which permits others to distribute, remix, adapt, build upon this work non-commercially, and license their derivative works on different terms, provided the original work is properly cited, appropriate credit is given, any changes made indicated, and the use is non-commercial. See: http://creativecommons.org/licenses/by-nc/4.0/.

ORCID iD

Zelalem Mehari Nigussie http://orcid.org/0000-0003-1015-7047

\section{REFERENCES}

1 DHHS OoARACO. Panel on antiretroviral guidelines for the use of antiretroviral agents in adults and adolescents living with HIV in services DoHaH. AIDS info, 2018.

2 Science Daily. Risk of HIV treatment failure present even in those with low viral load, 2013.

3 FMO. National guidelines for comprehensive HIV prevention, care, and treatment, 2017.

4 Ethiopia F. National consolidated guidelines for comprehensive HIV prevention, care, and treatment, 2018.

5 Health FMO. National guidelines for comprehensive HIV prevention, care, and treatment, 2017.

6 WHO. Consolidated guidelines on the use of antiretroviral drugs for treating and preventing HIV infection, 2016.

7 Gunda DW, Kidenya BR, Mshana SE, et al. Accuracy of who immunological criteria in identifying virological failure among HIVinfected adults on first line antiretroviral therapy in Mwanza, northwestern Tanzania. BMC Res Notes 2017;10:45.

8 WHO. Hiv treatment and care. fact sheet November 2015, 2015.

9 Institute NA. Virologic and immunologic monitoring Johns Hopkins University, 2018.

10 Science Daily. Risk of HIV treatment failure presents even in those with low viral load University of Montreal, 2013.

11 ORAC. Guidelines for the use of antiretroviral agents in adults and adolescents living with HIV management of the treatmentexperienced patient AIDS info, 2017.

12 Shirley Lecher JW, Peter N. Andreal progress with scale-up of HIV viral load monitoring -Seven sub-Saharan African countries, January 2015-June 2016 2016;65:1332-5.

13 UNAIDS. Global and regional HIV and AIDS statistics \& features UNAIDS Data 2018;2018.

14 Mahon C. Just $45 \%$ of young women in East and Southern Africa are virally suppressed. Available: https://www.avert.org/news/just-45young-women-east-and-southern-africa-are-virally-suppressed

$15 \mathrm{FMOH}$. Health sector development programme IV annual performance report, 2014. 
16 Brhane BG, Nibret E, Abay GK. Hiv/Aids treatment failure and its determinant factors among first line HAART patients at Felege-Hiwot referral Hospital, Bahir Dar, Northwest Ethiopia. J AIDS Clin Res 2017;8

17 Hailu GG, Hagos DG, Hagos AK, et al. Virological and immunological failure of HAART and associated risk factors among adults and adolescents in the Tigray region of northern Ethiopia. PLoS One 2018;13:e0196259.

18 Bayu B, Tariku A, Bulti A, et al. Destaw Fetene Teshome Northwest Ethiopia: a case-control study determinants of virological failure among patients on highly active antiretroviral therapy in University of Gondar referral hospital. HIVIAIDS - Research and Palliative Care 2017;9:153-9.

19 Mark Dybul ASF. Guidelines for using antiretroviral agents among HIV-infected adults and adolescents CDC, 2002.

20 Lilian Bulage IS, Ssewanyana I, Nankabirwa V, et al. Factors associated with virological non-suppression among HIV-positive patients on antiretroviral therapy in Uganda, August 2014-July 2015. BMC Infect Dis 2017;17.

21 Rupérez M, Pou C, Maculuve S, et al. Determinants of virological failure and antiretroviral drug resistance in Mozambique. J Antimicrob Chemother 2015;70:2639-47.

22 Fong R, Cheng AC, Vujovic O, et al. Factors associated with virological failure in a cohort of combination antiretroviral therapytreated patients managed at a tertiary referral centre. Sex Health 2013;10:442-7.

23 Carriquiry G, Giganti MJ, Castilho JL, et al. Virologic failure and mortality in older art initiators in a multisite Latin American and Caribbean cohort. J Int AIDS Soc 2018;21:e25088.

24 Groote ND. Age differences in viral suppression, antiretroviral therapy use, and adherence among HIV-positive men who have sex with men receiving medical care in the United States in national center for HIV/ AIDS VH, STD, and TB prevention. Medical Monitoring Project, 2016.

25 Kyaw NTT, Harries AD, Kumar AMV, et al. High rate of virological failure and low rate of switching to second-line treatment among adolescents and adults living with HIV on first-line art in Myanmar, 2005-2015. PLoS One 2017;12:e0171780.
26 Leng X, Liang S, Ma Y, et al. Hiv virological failure and drug resistance among injecting drug users receiving first-line art in China. BMJ Open 2014;4:e005886

27 Sithole Z, Mbizvo E, Chonzi P, et al. Virological failure among adolescents on art, Harare City, 2017- a case-control study. BMC Infect Dis 2018;18:469.

28 Ramadhani HO, Thielman NM, Landman KZ, et al. Predictors of incomplete adherence, virologic failure, and antiviral drug resistance among HIV-infected adults receiving antiretroviral therapy in Tanzania. Clin Infect Dis 2007;45:1492-8.

29 Haile D, Takele A, Gashaw K, et al. Predictors of treatment failure among adult antiretroviral treatment (art) clients in bale zone hospitals, South eastern Ethiopia. PLoS One 2016;11:e0164299.

30 Thejus T, Jeeja M, Jayakrishnan T. The functional status of patients with AIDS attending antiretroviral treatment center. Indian J Palliat Care 2009:15:57-60.

31 Desai M, lyer G, Dikshit RK. Antiretroviral drugs: critical issues and recent advances. Indian J Pharmacol 2012;44:288-98.

32 Dadi TL, Kefale AT, Mega TA, et al. Efficacy and tolerability of tenofovir disoproxil fumarate based regimen as compared to zidovudine based regimens: a systematic review and meta-analysis. AIDS Res Treat 2017;2017:1-7.

33 Campbell TB, Smeaton LM, Kumarasamy N, et al. Efficacy and safety of three antiretroviral regimens for initial treatment of HIV-1: a randomized clinical trial in diverse multinational settings. PLoS Med 2012;9:e1001290.

34 Delaugerre C, Ghosn J, Lacombe J-M, et al. Significant reduction in HIV virologic failure during a 15-year period in a setting with free healthcare access. Clin Infect Dis 2015;60:463-72.

35 Bello EJM, Correia AF, Marins JRP, et al. Predictors of virologic failure in HIV/AIDS patients treated with highly active antiretroviral therapy in Brasília, Brazil during 2002-2008. Drug Target Insights 2011;5:33-41.

36 Günthard HF, Saag MS, Benson CA, et al. Antiretroviral drugs for treatment and prevention of HIV infection in adults. JAMA 2016;316:191-210. 